\title{
Exploring the role of repetition and sensory elaboration in the imagination inflation effect
}

\author{
AYANNA K. THOMAS and JOHN B. BULEVICH \\ Washington University, St. Louis, Missouri \\ and \\ ELIZABETH F. LOFTUS \\ University of California, Irvine, California
}

\begin{abstract}
Two experiments were conducted to examine whether a misattribution of specific characteristicsor a misattribution of global familiarity underlies false memories as assessed through imagination inflation. Using the paradigm developed by Goff and Roediger (1998), we found that the proportion of false memories increased with repeated imagination, replicating the imagination inflation effect. False memories developed through imagination were greatest in conditions that forced participants to include sensory detail in their imaginings. Finally, conscious recollection more often accompanied false memories in perceptually detailed imagination conditions, whereas feelings of familiarity more often accompanied false memories in conditions that lacked sensory cues. These results suggest that imagination that contains more perceptual information leads to more elaborate memory representations containing specific characteristics that can be confused with actually performed actions. Confusion based on these representations, as opposed to confusion based on processing fluency, is more likely to lead to false memories.
\end{abstract}

Imagination as a cause of memory distortion has generated much recent interest. Researchers have demonstrated that memories for both childhood events and more recent actions are influenced by imagination (Garry, Manning, Loftus, \& Sherman, 1996; Goff \& Roediger, 1998). Typically, confidence in the occurrence of fictitious events increases after those events have been imagineda phenomenon called imagination inflation. An increase in source-monitoring errors after repeated imagining has also been used to demonstrate the imagination inflation effect. For example, Goff and Roediger found that participants erroneously remembered performing actions after only imagining those actions.

Although imagination inflation has been demonstrated repeatedly (Garry et al., 1996; Goff \& Roediger, 1998; Heaps \& Nash, 1999; Paddock et al., 1999; Thomas \& Loftus, 2002), the debate over the cause of the imagination inflation effect continues. Previous research suggests that imagination inflation can be accounted for by both the source-monitoring framework (Johnson, Hashtroudi, \& Lindsay, 1993) and familiarity misattribution theory (Jacoby, Kelley, \& Dywan, 1989). However, if familiar-

\footnotetext{
The results of these experiments have been presented at the 12th Annual Meeting of the American Psychological Society, Miami, June 2000, and at the 2nd Annual Northwest Conference on Cognition and Memory in Bellingham, WA, June 2000. This manuscript benefited from comments by Mary Ann Foley, Colleen Kelley, and Karen Mitchell. Correspondence concerning this article should be addressed to A. K. Thomas, One Brookings Drive, Box 1125, Psychology Department, Washington University, St. Louis, MO 63130-4899(e-mail: athomas@artsci.wustl.edu).
}

ity misattribution adequately accounts for imagination inflation by rendering the imagined event more familiar and available (Garry et al., 1996), then imagining itself may not be necessary to achieve the effect. If, however, imagination inflation is driven primarily by the misattribution of sensory and perceptual detail, then imagination would be key to the effect, and the source-monitoring framework would best account for this particular false memory phenomenon. The goal of the present study is to examine whether it is misattribution of discrete or specific memory characteristics, such as sensory detail, or misattribution of more general memory characteristics, such as familiarity, that drives the imagination inflation effect.

\section{The Source-Monitoring Framework and False Memories}

The source-monitoring framework has often been used to account for false memories that arise in a variety of domains. According to the source-monitoring framework, thoughts, images, and feelings that are experienced as memories are attributed to particular sources of past experiences (Lindsay \& Johnson, 2000). The assessment of these and other qualitative characteristics, such as the amount and quality of sensory information (e.g., color and sound), contextual information (e.g., time and place), semantic detail, and cognitive operations, allows one to determine the credibility of a memory (Johnson et al., 1993; Johnson \& Raye, 1981). Of particular importance to the false memory debate and, more specifically, to imagination inflation, is the association of these 
features with perceived or imagined events. For example, perceived events often incorporate more perceptual and sensory detail, whereas imagined events are associated more strongly with cognitive operations (Johnson, Foley, Suengas, \& Raye, 1988).

Research into the differences between perceived and imagined events has also revealed that people remembered what they felt and thought about perceived events better than they did about imagined ones. Furthermore, rated clarity of memories, thoughts, and feelings decreased faster for imagined than for perceived events (Suengas \& Johnson, 1988). Evidently, we rely on different characteristics and variations in cue strength to aid in our ability to monitor the source of memories.

Source misattribution errors often occur when cues associated with events are not encoded or when memory characteristics between two or more sources are or become similar. For example, Johnson, Foley, and Leach (1988) found that when participants either imagined hearing words in a confederate's voice or actually heard words in a confederate's voice, they later had more difficulty discriminating the source of those words than when they were tested with words heard in the confederate's voice and words imagined in their own voices. Similarly, Henkel, Franklin, and Johnson (2000) found that external sensory detail negatively affected source-monitoring errors when perceived and imagined events were compared. External sensory detail implemented by coupling imagery with the sound of an event led to more sourcemonitoring errors than did imagery alone.

\section{Misattribution of Familiarity and False Memories}

Perhaps the imagination inflation effect is driven primarily not by a misattribution of specific memory characteristics such as sensory detail, but by a misattribution of global familiarity. Jacoby and Dallas (1981) suggested that perceptual fluency serves as a basis for a feeling of familiarity and that familiarity biases recognition. When participants were presented with a list of famous and nonfamous names and asked to judge the fame of the names after a delay, they were more likely to endorse previously studied nonfamous names as famous than to do so with new nonfamous names (Jacoby, Kelley, Brown, \& Jasechko, 1989). Jacoby, Kelley, et al. (1989) argued that the previous exposure to old nonfamous names increased their familiarity and that this increase in familiarity led to a bias in responding. Prior exposure also affects judgments of affect (Moreland \& Zajonc, 1977) and ease of perception (Jacoby, Allan, Collins, \& Larwill, 1988). These findings suggest that prior exposure affects how easily information is processed and that ease of processing may influence source judgments.

Garry et al. (1996) has argued that prior exposure of a fictitious event through imagination may be the primary cause of the imagination inflation effect, because global familiarity of the event increases. When subjects are asked to rate their confidence in the occurrence of an event, they may take the familiarly of the event, derived through imagination, to mean that it happened. Garry et al. (1996) likened imagination inflation to the "sleeper effect" (Pratkanis, Greenwald, Leippe, \& Baumgardner, 1988), in which content and source eventually become dissociated, and a proposition that would immediately have been judged invalid may be judged true after some delay. Further support for the familiarity misattribution explanation of imagination inflation comes from studies in which confidence that a fictitious event has been experienced increases after imagining, regardless of specific details of the imagination (Garry, Frame, \& Loftus, 1999). Imagining either oneself or another person in an event led to increased confidence that the event had been previously experienced.

\section{The Present Study}

The question of interest for the present study is whether global misattribution of familiarity or misattribution of more specific memory characteristics drives imagination inflation. If discrete and specific characteristics, such as sensory detail or cognitive operations, drive imagination inflation, then the effect is contingent on more elaborate memory representations and is best accounted for by the source-monitoring framework. If, however, the effect is driven by general characteristics, such as a global assessment of processing ease, then these kinds of false memories may arise outside of imagination. The specific details of the imagination or repetition activity should be relatively unimportant, provided that misattribution errors are based on increased familiarity with the action.

Previous research has determined that when witnesses are pressed to elaborate on perceptual characteristics of suggested events, an increase in the occurrence of false memories for those events is found (Drivdahl \& Zaragoza, 2001). Participants who answered questions that encouraged them to elaborate on the location and physical appearance of items were much more likely to later claim that they "definitely" remembered seeing the suggested item. By forcing participants to elaborate on perceptual characteristics through imagination, a similar pattern should emerge in an imagination inflation paradigm. Researchers have also posited that high imagers form a more vivid visual image, which makes source discrimination difficult (Dobson \& Markham, 1993). These findings suggest that forcing all imagers (both high and low) to form more vivid visual images would lead to poorer source discrimination and more false memories. If more vivid visual images result in more false memories, then a misattribution of specific perceptual characteristics would be the most likely cause of false memories, supporting the source-monitoring account of imagination inflation.

We hypothesized that when participants are provided with more sensory and perceptual detail during imagination, they will be more likely to create false memories, because false memories are driven by the misattribution 
of specific memory characteristics as described by the source-monitoring framework. We used a paradigm modeled after Goff and Roediger (1998) in which participants performed or imagined simple actions in a first session. In a second session, participants imagined performing a variety of actions, sometimes repeatedly. Session 2 activity varied to enhance or diminish specific characteristics, such as sensory information. To test whether familiarity misattribution could also adequately account for false memories, a condition in which perceptual detail was reduced was also developed. In a third and final session, the participants indicated whether they had performed or imagined actions during Session 1. We expected that more elaborate imagining would lead to more false memories, in support of the findings that perceptual elaboration increases the false memory effect (Drivdahl \& Zaragoza, 2001).

\section{EXPERIMENT 1}

\section{Method}

Participants. The participants were 145 University of Washington undergraduates. They received extra credit toward an introductory psychology course. The participants were tested in groups of 6 to 10.

Design. The experiment was based on a $2 \times 2 \times 3 \times 3$ mixed design. The between-subjects variable was type of imagining (simple, elaborate). The within-subjects variables were type of action (familiar, bizarre), initial presentation condition of the action statement (performed, imagined, or not presented), and number of imaginings in the second session $(0,1,5)$. The dependent variable was source-monitoring accuracy.

Materials and Procedure. We used 72 critical action statements. Forty were taken from Thomas and Loftus (2002), and 32 were constructed for this experiment. Actions ranged from familiar to bizarre, as determined by an independent group of participants who rated the action statements on a scale of 1 (not bizarre at all) to 7 (extremely bizarre). The mean rating for actions designated as familiar was 1.5; the mean rating for actions designated as bizarre was 6.0. The action statements were divided equally, so that all the participants were presented with the same number of familiar and bizarre action statements. The test materials (given 2 weeks later) included all 72 of the critical action statements.

During Session 1, the participants were randomly assigned to one of nine counterbalancing conditions to control for the possibility of presentation order effects and to ensure that each action statement was performed, imagined, or not presented during the first session and was imagined zero, one, or five times during the second session. Half of the actions presented were familiar, and half were bizarre. These procedures followed those established by Thomas and Loftus (2002). Participants tested together during Session 1 were tested together during Sessions 2 and 3. Participants tested at the same time were presented with the same order of action statements in the first and second sessions. Thus, participants in the same group performed and imagined performing the same actions.

Session 1: Encoding of events. Objects necessary for performing all 72 critical actions were set out for each participant. Each participant sat alone at a table. The participants were informed that they would be asked to either perform or imagine performing simple actions using the materials in front of them. Before action statements were read, the experimenter acquainted the participants with the objects. The participants were shown each object individually and were aware of each object's location on the table. Forty-eight actions were either performed or imagined by the participants during Session 1 . Thus, the critical action statements were divided in such a way that 24 actions were performed, 24 actions were imagined, and 24 actions were not presented at all during Session 1.

The participants were informed that they would hear action statements that involved simple requests. For some statements, they would be asked to perform the actions, and for others they would be asked to imagine them. They were told that, if instructed to imagine, they were to imagine themselves performing the action. They were told to use the materials on the table in front of them when performing actions, but not to interact with the materials when engaged in imagining. The 48 action statements ( 24 performed and 24 imagined) were read aloud by the experimenter. The participants were given $15 \mathrm{sec}$ to either imagine or perform each action and were instructed to use the full 15 -sec interval. After the 48 action statements had been presented, the participants were reminded of the second session and then dismissed.

Session 2: Imagining. The participants returned $24 \mathrm{~h}$ later for the second session. In this session, all action statements presented were imagined. The participants were not exposed to any objects from Session 1. Fifteen seconds were given for each imagining. Of the 72 critical action statements, 24 were not imagined at all, 24 were imagined one time, and 24 were imagined five times. Furthermore, of the 24 actions performed in Session 1, eight were not imagined, 8 were imagined one time, and 8 were imagined five times. The same was true for actions imagined in Session 1 and for actions not presented in Session 1. The participants imagined a total of 144 actions. In addition, no 2 action statements were imagined consecutively.

In this session, action statements were read aloud, and the participants were instructed to use either simple imagining or elaborate imagining. (For instructions used in the simple and elaborate imagining conditions, see the Appendix.) The participants were given $15 \mathrm{sec}$ for each imagining-that is, the timing began as the experimenter began reading the action statement, so all actions, regardless of condition, were given the same presentation time. To help ensure that the participants actually performed the imagining, after each action statement was imagined the participants had to rate the vividness of the imagination $(1=$ not vivid $; 2=$ slightly vivid; $3=$ some what vivid; $4=$ very vivid $; 5=$ extremely vivid $)$. At the end of this session, the participants were reminded of the third session and dismissed.

Session 3: Testing. Two weeks later, the participants returned and were given several measures designed to assess memory for Session 1 activity. All 72 critical actions were presented in a fixed random order. The participants were explicitly instructed to answer questions based solely on what they remembered from Session 1. For each action, the participants were asked whether it had been presented (either imagined or performed) during Session 1. If they answered "yes," the participants then indicated whether they had performed or imagined that action. This constituted a source memory test.

After the participants determined whether the action had been performed or imagined, they made remember/know (R/K) judgments. The participants made R/K judgments only for actions reported as having been performed in Session 1. The participants were instructed to make an R judgment for actions for which they had a vivid memory of the actual presentation. That is, if they were able to bring to mind some recollection of what had occurred at the time of encoding, an R judgment should be given. They were instructed to reserve $\mathrm{K}$ judgments for actions that they were sure had been presented but for which they lacked the feeling of remembering an actual occurrence of the presentation (Gardiner, 1988; Rajaram, 1993; Tulving, 1985).

\section{Results}

False memories for novel actions. We examined the mean proportions of responses in which the participants claimed to have performed actions (did responses) that were not presented during Session 1. As can be seen in 
Table 1

Experiment 1: Mean Proportion of Did Responses and Remember/Know Judgments for Actions Not Presented or Imagined in Session 1

\begin{tabular}{|c|c|c|c|c|c|c|c|c|}
\hline \multirow[b]{3}{*}{ Session 2 Activity } & \multicolumn{4}{|c|}{ Simple } & \multicolumn{4}{|c|}{ Elaborate } \\
\hline & \multicolumn{2}{|c|}{ Familiar } & \multicolumn{2}{|c|}{ Bizarre } & \multicolumn{2}{|c|}{ Familiar } & \multicolumn{2}{|c|}{ Bizarre } \\
\hline & $M$ & $\overline{S E}$ & $M$ & $\overline{S E}$ & $M$ & $\overline{S E}$ & $M$ & $\overline{S E}$ \\
\hline \multirow{2}{*}{\multicolumn{9}{|c|}{$\begin{array}{l}\text { Action not presented in Session } 1 \\
\text { Imagined } 0 \text { times }\end{array}$}} \\
\hline & & & & & & & & \\
\hline Did & .01 & .01 & .00 & .00 & .01 & .01 & .01 & .01 \\
\hline Remember & .00 & & .00 & & .00 & & .00 & \\
\hline Know & .01 & & .00 & & .01 & & .01 & \\
\hline \multicolumn{9}{|l|}{ Imagined 1 time } \\
\hline Did & .04 & .01 & .01 & .01 & .11 & .02 & .07 & .02 \\
\hline Remember & .03 & & .01 & & .08 & & .05 & \\
\hline Know & .01 & & .00 & & .03 & & .02 & \\
\hline \multicolumn{9}{|l|}{ Imagined 5 times } \\
\hline Did & .13 & .03 & .10 & .02 & .16 & .02 & .13 & .02 \\
\hline Remember & .10 & & .06 & & .14 & & .10 & \\
\hline Know & .03 & & .04 & & .02 & & .03 & \\
\hline \multicolumn{9}{|l|}{ Action imagined in Session 1} \\
\hline \multicolumn{9}{|c|}{ Imagined 0 times } \\
\hline Did & .04 & .01 & .03 & .03 & .02 & .01 & .02 & .01 \\
\hline Remember & .02 & & .01 & & .00 & & .00 & \\
\hline Know & .02 & & .02 & & .02 & & .02 & \\
\hline \multicolumn{9}{|l|}{ Imagined 1 time } \\
\hline Did & 08 & .01 & .07 & .01 & .11 & .02 & .08 & .02 \\
\hline Remember & .04 & & .03 & & .06 & & .06 & \\
\hline Know & .04 & & .04 & & .05 & & .02 & \\
\hline \multicolumn{9}{|l|}{ Imagined 5 times } \\
\hline Did & .10 & .02 & .09 & .02 & .15 & .02 & .17 & .02 \\
\hline Remember & .09 & & .08 & & .13 & & .10 & \\
\hline Know & .01 & & .01 & & .02 & & .07 & \\
\hline
\end{tabular}

the top section of Table 1, both number and type of imagining affected false $d i d$ responses. Notice that participants almost never said that they had performed novel actions if they had not imagined those actions in Session 2. However, if participants had imagined actions five times, they were much more likely to falsely claim that the actions had been performed. After five imaginings, the proportions of false did responses were between .10 and .16, depending on the particular type of imagination activity and on whether the action was familiar or bizarre. Elaborate imagination led to more false $d i d$ responses than did simple imagination, and imagination inflation was somewhat larger for familiar than for bizarre actions.

To analyze these results statistically, a 3 (number of imaginings: $0,1,5) \times 2$ (type of imagination: elaborate, simple) $\times 2$ (type of action: familiar, bizarre) mixed ANOVA was performed on false did responses to actions not presented in Session 1. (Unless otherwise stated, for all reported significant statistical tests, $p<.05)$. A main effect of number of imaginings was found $[F(2,286)=$ $52.64, M S_{\mathrm{e}}=0.02$, from .01 to .06 to .13 for 0,1 , and 5 imaginings, respectively]..$^{1}$ In addition, a main effect of type of imagining was found [simple, .05 ; elaborate, .08 ; $\left.F(1,143)=7.19, M S_{\mathrm{e}}=0.02\right]$. We found that the interaction between type and number of imaginings was significant $\left[F(2,286)=3.36, M S_{\mathrm{e}}=0.02\right]$. False $d i d$ responses increased with repetition more for the participants who had engaged in elaborate imagination $(.01, .09, .15)$ than for those who had engaged in simple imagination (.01, $.03, .12)$. In addition, we found a main effect of type of action $\left[F(1,143)=7.08, M S_{\mathrm{e}}=0.02\right]$. That is, the participants were more likely to falsely claim that a familiar action had been presented (.08) in comparison with a bizarre action (.05). Finally, the interaction between type of imagining and type of action was not significant $(F<1)$.

$\mathbf{R} / \mathbf{K}$ judgments for novel actions. We also explored whether phenomenological experience, as measured through R/K judgments, was affected by type and number of Session 2 imaginings. The participants made an $\mathrm{R} / \mathrm{K}$ judgment only if they indicated that they had performed the action during Session 1. As can be seen in the top section of Table 1 , the participants never gave $\mathrm{R}$ judgments to novel actions not imagined in Session 2. However, after five imaginings in Session 2, the proportion of $\mathrm{R}$ judgments was between .06 and .14, depending on the particular type of imagination activity and on whether the action was familiar or bizarre. Elaborate imagining led to more $\mathrm{R}$ judgments than did simple imagining.

A 3 (number of imaginings: $0,1,5) \times 2$ (type of imagination: elaborate, simple) $\times 2$ (type of action: familiar, bizarre) mixed ANOVA on the R judgments, divided by the total number of actions in a condition, yielded an effect of number of imaginings $[0, .04, .10 ; F(2,286)=$ $\left.41.80, M S_{\mathrm{e}}=0.03\right]$. Furthermore, type of action significantly affected the proportion of $R$ judgments, in that 
participants gave familiar actions (.06) more $\mathrm{R}$ judgments than they did bizarre actions $(.04)[F(1,143)=$ $\left.5.74, M S_{\mathrm{e}}=0.01\right]$. Finally, the effect of type of imagination was significant [simple, .05 ; elaborate, $.07 ; F(1,143)=$ $\left.7.63, M S_{\mathrm{e}}=0.01\right]$. The interaction between type and number of imaginings was marginally significant [simple, $.01, .03, .08$; elaborate, $.01, .07, .12 ; F(2,286)=2.55$, $\left.M S_{\mathrm{e}}=0.01, p=.08\right]$. No other interactions were significant. $^{2}$

False memories for imagined actions. As was previously mentioned, false $d i d$ responses were measured in two ways. We also examined the increase in the proportion of false did responses to actions that were imagined in Session 1 but never performed. As can be seen in the bottom section of Table 1, the proportion of false did responses made after five acts of elaborate imagination was .15 for familiar actions and .17 for bizarre actions. With no imagining in Session 2, the proportion of false did responses was .02-.04, depending on the type of action and the imagining condition.

To analyze these results statistically, a 3 (number of imaginings: $0,1,5) \times 2$ (type of imagination: elaborate, simple) $\times 2$ (type of action: familiar, bizarre) mixed ANOVA was performed on these false did responses. The difference between types of imagination was significant $\left[F(1,143)=4.30, M S_{\mathrm{e}}=0.03\right]$. As with new actions, elaborate imagination (.09) led to more false did responses to actions imagined in Session 1 than did simple imagination (.07). The effect of number of imaginings was also significant $[.03, .09, .13 ; F(2,286)=26.43$, $\left.M S_{\mathrm{e}}=0.03\right]$. Furthermore, the interaction between type and number of imaginings was significant $[F(2,286)=$ $3.80, M S_{\mathrm{e}}=0.03$ ], demonstrating that the participants who had engaged in elaborate imagination $(.02, .10, .16)$ were more likely to increase false $d i d$ responses as repetition of imagining increased, in comparison with those who had engaged in simple imagination $(.04, .08, .10)$. Finally, unlike for novel actions, there was no significant difference between types of action $(F<1)$, although in almost every case, familiar actions elicited more false did responses than did bizarre actions. No other interactions were significant $(F<1)$.

$\mathbf{R} / \mathbf{K}$ judgments for imagined action. As can be seen in the bottom section of Table $1, \mathrm{R}$ judgments increased as the number of imaginings increased, from 0 to .13 for familiar actions and from 0 to .10 for bizarre actions in the elaborate imagination condition. As with actions not presented, we found that as the number of imaginings increased, so did the proportion of $\mathrm{R}$ judgments $[.01, .05$, $\left..10 ; F(2,286)=20.12, M S_{\mathrm{e}}=0.02\right]$. A marginally significant difference was found for type of action $[F(1,143)=$ $3.65, M S_{\mathrm{e}}=0.01, p=.06$ ], from .05 for bizarre to .06 for familiar. No significant main effect of type of imagination was found, although, as can be seen in Table 1, elaborate imagination (.06) did elicit more $\mathrm{R}$ judgments than did simple imagination (.05). The interaction between number of imaginings and type of action was not significant $(F<1)$.

\section{Discussion}

To reiterate the main results, we first showed that repeatedly imagining an action increased the likelihood that participants would erroneously claim to have performed the action. Five instances of simple imagining led to $13 \%$ and $10 \%$ false $d i d$ responses for novel familiar and bizarre actions, respectively. This result replicates earlier work by Thomas and Loftus (2002) in showing that simple imagining causes imagination inflation for both familiar and bizarre actions. This experiment also demonstrated that elaborate imagining led to even greater imagination inflation. Five imaginings led to $16 \%$ and $13 \%$ false did responses for novel familiar and bizarre actions, respectively.

One explanation of why elaborate imagining elicits more false did responses is that it forces participants to rehearse specific sensory information from multiple modalities. Later, when the action is tested, it comes to mind with a richer, more detailed representation and is consequently less distinguishable from the representations of actions that were truly performed. Of course, it is also true that the elaborate imagination activity involves repeated mention of the object in the sentence. In the elaborate imagination instruction involving the frog, for example, the frog is mentioned three times: once in the sentence about kissing, once in the sentence about its color, and once in the sentence about the tactile experience. Perhaps the repetition of the key object enhanced its familiarity, and this enhanced familiarity drove the later source-monitoring difficulty. These considerations, in part, motivated Experiment 2.

\section{EXPERIMENT 2}

To determine whether the repetition of critical objects in the action statement drove imagination inflation, a new imagination procedure was devised, in which the participants generated individual imagination scripts. In the individual imagination condition, the participants were instructed to create imagination scripts that were two sentences long and that focused on two different sensory modalities. This allowed for the development of elaborate imagination scripts without the repeated auditory presentation of key objects in the action, as was done in the elaborate imagination condition in Experiment 1. The participants who engaged in individual imagination were read a one-sentence script (e.g., "Imagine kissing the frog") and then added their own two-sentence scripts to their act of imagining. Thus, both individual and elaborate imagining incorporated sensory characteristics; however, one condition provided these characteristics to the participants along with repetition of key objects in the action, whereas in the other the participants developed their own.

Experiment 2 was also designed to more thoroughly investigate familiarity misattribution as a contributor to false did responses. Experiment 1 demonstrated that when participants were provided with sensory and perceptual 
detail, they were more susceptible to false $d i d$ responses. These results provide evidence that participants used qualitative characteristics of memories in the act of remembering. However, if fluency drives familiarity misattribution, then repeated presentation that increases fluent processing of action statements should increase false did responses, regardless of imagining. In Experiment 2, we investigated whether familiarity, in the absence of more specific cues, can generate an inflation effect similar to that seen when sensory cues developed in imagination are misattributed. A text presentation condition is compared with the imagining conditions of Session 2.

\section{Method}

Participants. The participants were 303 University of Washington undergraduates. They received extra credit toward an introductory psychology course. The participants were tested in groups of 6 to 10 .

Design. The experiment was based on a $3 \times 3 \times 3$ mixed design. The between-subjects variable was type of presentation (elaborate, individual, text). The within-subjects variables were initial presentation condition of the action statement (performed, imagined, not presented) and number of imaginings $(0,1,5)$ in the second session. The dependent variable was source-monitoring accuracy.

Materials and Procedure. Fifty-four bizarre action statements were used in this experiment. Actions were rated as bizarre by an independent group of 35 participants.

Session 1: Encoding of events. Session 1 in Experiment 2 was identical to that of Experiment 1. The participants performed or imagined each action for $15 \mathrm{sec}$.

Session 2: Repeated presentation. The participants returned $24 \mathrm{~h}$ later for the second session. In this session, all action statements presented were imagined or read. The participants elaborately imagined, individually imagined, or read action statements. The elaborate imagination instructions were identical to those used in Experiment 1 and can be viewed in the Appendix, along with the instructions given in the individual imagination condition.

The participants in the text presentation condition were told to read and reread the action (i.e., "kiss the frog") for the full $15 \mathrm{sec}$ of presentation. A fixation point for $500 \mathrm{msec}$ preceded the action statement. The action statement was then presented for $15 \mathrm{sec}$ in black 40-point font against a white background. The statements were single sentences similar to those used in simple imagining in Experiment 1; however, they were not prefaced with the word "imagine." To ensure that the participants actually engaged in the task, at the end of the $15 \mathrm{sec}$, they were asked to report (by circling the number) the serial position (or positions) of the longest word or words in the statement. For example, in "kiss the frog," the participants would report " 1 " and " 3 " as their answers. Pilot data suggested that this task forced the participants to read actions and process on a global level without engaging in spontaneous imagery.

Of the 54 action statements, 18 were not imagined at all, 18 were imagined one time, and 18 were imagined five times. The participants imagined or read a total of 108 action statements. At the end of this session, the participants were reminded of the third session and dismissed.

Session 3: Testing. The testing session, which occurred 2 weeks later, was identical to that in Experiment 1. The participants completed source-monitoring and $\mathrm{R} / \mathrm{K}$ judgments.

\section{Results}

False memories for novel actions. As can be seen in Table 2, both elaborate and individual imagination led to more false $d i d$ responses than did text presentation. After five acts of elaborate imagination in Session 2, the pro-

Table 2

Experiment 2: Mean Proportion of Did Responses and Remember/Know Judgments for Actions Not Presented or Imagined in Session 1

\begin{tabular}{|c|c|c|c|c|c|c|}
\hline \multirow[b]{2}{*}{ Session 2 Activity } & \multicolumn{2}{|c|}{ Elaborate } & \multicolumn{2}{|c|}{ Individual } & \multicolumn{2}{|c|}{ Text } \\
\hline & $M$ & $S E$ & $M$ & $S E$ & $M$ & $S E$ \\
\hline \multicolumn{7}{|c|}{ Action not presented in Session 1} \\
\hline \multicolumn{7}{|l|}{ Presented 0 times } \\
\hline Did & .01 & .01 & .01 & .01 & .01 & .01 \\
\hline Remember & .00 & & .00 & & .01 & \\
\hline Know & .01 & & .01 & & .00 & \\
\hline \multicolumn{7}{|l|}{ Presented 1 time } \\
\hline Did & .04 & .01 & .03 & .01 & .02 & .01 \\
\hline Remember & .03 & & .03 & & .02 & \\
\hline Know & .01 & & .00 & & .00 & \\
\hline \multicolumn{7}{|l|}{ Presented 5 times } \\
\hline Did & 18 & .02 & .13 & .02 & .04 & .01 \\
\hline Remember & .15 & & .12 & & .02 & \\
\hline Know & .03 & & .01 & & .02 & \\
\hline \multicolumn{7}{|l|}{ Action imagined in Session 1} \\
\hline \multicolumn{7}{|l|}{ Presented 0 times } \\
\hline Did & .06 & .01 & .07 & .01 & .07 & .01 \\
\hline Remember & .04 & & .04 & & .05 & \\
\hline Know & .02 & & .03 & & .02 & \\
\hline \multicolumn{7}{|l|}{ Presented 1 time } \\
\hline Did & .13 & .02 & .20 & .02 & .07 & .01 \\
\hline Remember & .11 & & .17 & & .05 & \\
\hline Know & .02 & & .03 & & .02 & \\
\hline \multicolumn{7}{|l|}{ Presented 5 times } \\
\hline Did & .17 & .02 & .27 & .02 & .10 & .01 \\
\hline Remember & .17 & & .21 & & .06 & \\
\hline Know & .00 & & .06 & & .04 & \\
\hline
\end{tabular}


portion of false did responses made to actions never presented in Session 1 was .18. For individual imagination, the proportion was .13. The proportion of false did responses after five acts of text presentation was only .04.

To analyze these data statistically, a 3 (number of presentations: $0,1,5) \times 3$ (type of presentation: elaborate, individual, text) mixed ANOVA was performed on false did responses to novel actions. We found a main effect of number of presentations, demonstrating that repeated presentation increased false did responses [.01, .03, .12; $\left.F(2,600)=112.46, M S_{\mathrm{e}}=0.01\right]$. A significant main effect of type of Session 2 activity was also found $[F(2,300)=$ $20.23, M S_{\mathrm{e}}=0.01$ ], from .02 in text presentation to .06 in individual imagination to .08 in elaborate imagination. In addition, the interaction between type and number of presentations was significant $\left[F(4,600)=18.85, M S_{\mathrm{e}}=\right.$ $0.02]$, demonstrating that the participants who had engaged in imagination (elaborate, .01, .04, .18; individual, $.01, .03, .13$ ) were more likely to produce false $d i d$ responses than were those who had engaged in text presentation $(.01, .02, .04)$.

Simple effects analyses revealed a marginal interaction between type and number of imaginings when the elaborate condition was compared with the individual condition $\left[F(2,346)=2.56, M S_{\mathrm{e}}=0.03, p=.07\right]$. Elaborate imagination led to more false $d i d$ responses as the number of imaginings increased. Similarly, a significant interaction between type and number of presentations was found when elaborate imagination was compared with text presentation $\left[F(2,390)=38.10, M S_{\mathrm{e}}=0.03\right]$. When individual imagination was compared with text presentation, a significant interaction between type and number of presentations was again found $\left[F(2,464)=23.48, M S_{\mathrm{e}}=\right.$ $0.01]$. In all instances, text presentation led to the fewest false $d i d$ responses, and the increase in false $d i d$ responses was not as great in the text presentation condition as in the imagination conditions. Although imagination conditions produced larger effects on source memory, an analysis of the text presentation condition revealed a significant main effect of number of presentations, demonstrating that the repetition of text in Session 2 also led to an increase in false did responses $[.01, .02, .04 ; F(2,254)=$ $\left.11.03, M S_{\mathrm{e}}=0.01\right]$.

$\mathbf{R} / \mathbf{K}$ for novel actions. Table 2 illustrates that as the number of presentations increased, the proportion of $\mathrm{R}$ judgments to actions not presented in Session 1 but reported as having been performed also increased, which is consistent with the findings of the previous experiment. This main effect was significant when a 3 (number of imaginings: $0,1,5) \times 3$ (type of imagination: elaborate, individual, text) mixed ANOVA was performed on the total $\mathrm{R}$ judgments divided by the total number of new actions in a condition $\left[0, .03, .10 ; F(2,600)=24.48, M S_{\mathrm{e}}=\right.$ $0.03]$. We also found a main effect of type of Session 2 presentation $\left[F(2,300)=5.31, M S_{\mathrm{e}}=0.03\right]$. The participants who had engaged in elaborate imagination (.06) and individual imagination (.05) were more likely to pro- duce $\mathrm{R}$ judgments than were those in the text presentation condition (.02). Furthermore, the interaction between type and number of presentations was significant $\left[F(4,600)=6.68, M S_{\mathrm{e}}=0.02\right]$, demonstrating that the participants who had engaged in imagination (elaborate, $0, .03, .15$; individual, $0, .03, .12$ ) produced more $\mathrm{R}$ responses to novel actions than did the participants who had engaged in text presentation $(.01, .02, .02)$.

False memories for imagined actions. As the bottom section of Table 2 illustrates, false did responses to actions imagined in Session 1 again were affected by type and number of Session 2 presentations. The proportion of false did responses after five actions of elaborate imagination was .17. After five individual imaginings, the proportion was .27. After the action was read five times in the text presentation condition, the proportion was .10. A 3 (number of presentations: $0,1,5) \times 3$ (type of presentation: elaborate, individual, text) mixed ANOVA yielded a significant effect of type of presentation $[F(2,300)=$ $\left.23.54, M S_{\mathrm{e}}=0.03\right]$. Individual imagination led to the most false did responses (.18), followed by elaborate imagination (.12) and then text presentation (.08). In addition, as in all of the previous cases, we found a significant main effect of number of presentations $[.07, .13, .18$; $\left.F(2,600)=63.06, M S_{\mathrm{e}}=0.01\right]$. Finally, a significant interaction between type and number of presentations was found $\left[F(4,600)=14.80, M S_{\mathrm{e}}=0.01\right]$, demonstrating that the participants who engaged in imagination (elaborate, $.06, .13, .17$; individual, $.07, .20, .27$ ) were more likely to produce false $d i d$ responses than were those in the text presentation condition $(.07, .07, .10)$.

Simple effects analyses comparing individual and elaborate imagination demonstrated that, unlike for actions not presented in Session 1, the increase in false did responses was greater in the individualimagination condition than in the elaborate imagination condition $[F(2,346)=4.64$, $\left.M S_{\mathrm{e}}=0.02\right]$. Again, although only a small effect, the increase in false did responses to imagined actions was significant when the text presentation condition was considered alone $\left[F(2,254)=4.57, M S_{\mathrm{e}}=0.01\right]$.

$\mathbf{R} / \mathbf{K}$ for imagined actions. Turning our attention to $R$ judgments given to false did responses to imagined actions, a 3 (number of imaginings: $0,1,5) \times 3$ (type of imagining: elaborate, individual, text) mixed ANOVA found that as the number of presentations increased, so did the proportion of $\mathrm{R}$ judgments $[.04, .11, .15$; $\left.F(2,600)=12.26, M S_{\mathrm{e}}=0.05\right]$. Furthermore, we found a main effect of type of presentation $[F(2,300)=7.96$, $\left.M S_{\mathrm{e}}=0.09\right]$. The imagination conditions (elaborate, .11; individual, .14) led to more $\mathrm{R}$ responses in comparison with the text presentation condition (.05). The interaction between type and number of presentations was also significant $\left[F(4,600)=3.16, M S_{\mathrm{e}}=0.07\right]$, demonstrating that the participants who had engaged in imagination (elaborate, $.04, .11, .17$; individual, $.04, .17, .21$ ) produced more $\mathrm{R}$ responses than did those in the text presentation condition $(.05, .05, .06)$. 


\section{Discussion}

When participants created their own enhanced imagination scripts in the individual imagination condition, they were as likely (if not more likely) to create false memories as participants who were provided elaborated scripts in the elaborate condition and those who experienced no sensory elaboration, as in the text presentation condition. Thus, although the repetition of key objects in the elaborate imagination scripts may have increased familiarity with those objects, that increase in familiarity did not account for the imagination inflation effect in the elaborate imagination condition. When participants were instructed to elaborate but were not provided with scripts that explicitly restated key objects, the same pattern of results emerged.

Unexpectedly, the individual imagination condition led to a much larger imagination inflation effect for actions imagined in Session 1 in comparison with both the elaborate imagination and text presentation conditions. One possible explanation of this is that the presence of actual objects in Session 1 might have facilitated the generation of imagination scripts in Session 2. The participants may have developed imagination scripts based in part on the imagination in which they had engaged during Session 1 and in part on the presence of the object in Session 1 . Having the stimuli present in Session 1 may have aided in the mental representation of the actions, despite the fact that the participants did not touch them. Unfortunately, our data do not speak directly to why individual imagination acted so strongly on actions imagined in Session 1. Regardless, perceptual elaboration, whether selfgenerated or provided by the experimenter, led to more false $d i d$ responses than did no elaboration.

Finally, as was found in the text presentation condition, no elaboration did produce a modest effect on false $d i d$ responses. These results suggest that the repetition of the action statement in Session 2 did increase global familiarity, and a small part of the imagination inflation effect can be accounted for by familiarity misattribution, but elaborated imagination seems critical to the false memory effects described in the literature.

\section{GENERAL DISCUSSION}

We showed in both experiments that, when participants were asked to include sensory information in imagination scripts, the proportion of false did responses increased. Imagination inflation was greater when participants elaborately imagined performing actions, whether their imagination was guided by the researcher (as in Experiments 1 and 2) or individually generated (Experiment 2 only). When false did responses were given, the large majority were assigned an $\mathrm{R}$ judgment, indicating that the participants had the experience of a real recollection.

When sensory information was removed from Session 2 activity (as in the text presentation condition), there was minimal inflation. This finding suggests that people erroneously claim that actions were performed because they misattribute discrete memory characteristics. Although a misattribution of more global characteristics, such as familiarity, also led to distortions in memory (as in the text presentation condition), this effect was modest. We propose that when participants elaborately imagined actions, an increase in false memories was observed because elaboration induced participants to form more detailed and elaborated representations that can be formed only through imagination. Thus, the nature of processing actions seems more important than mere repetition of those actions, just as the nature of processing was more important for Drivdahl and Zaragoza (2001).

According to the source-monitoring framework (Johnson et al., 1993), people use memory of sensory perceptual cues and memory for cognitive operations to discriminate perceived events from imagined ones. The increase in sensory cues in the elaborate imagination condition may have influenced participants toward erroneously claiming that imagined actions and actions not presented in Session 1 had been performed. By providing perceptual elaborations or by having participants generate their own, the imaginings may have become so detailed that the resulting mental image was similar to the perceptual encoding of an action that had been performed. Thus, as was expected, by having participants engage in more elaborate imaginings, all of them behaved very much like high imagers and produced more source misattribution errors (Dobson \& Markham, 1993).

It should be noted that false imagined responses to actions not presented in Session 1 also increased with repeated imagination, and that more elaborate imagination conditions led to more false imagined responses. Although not reported in the Results sections, the increase in false imagined responses was significant in both experiments. A possible explanation of this increase in false imagined responses is that imagining in Session 2 led to an increase in the cognitive operations associated with actions. This explanation is also consistent with the source-monitoring framework. Because cognitive operations are cues more closely associated with imagined events, participants may have been more likely to erroneously claim that new actions had been imagined. Although not the central focus of this article, these results provide further support that people rely on discrete and specific memory characteristics when making decisions about their memories.

However, false imagined responses to nonpresented actions provide support for an alternative explanation of the imagination inflation effect. Because the act of imagining is present in both Sessions 1 and 2 and two thirds of all actions in both experiments are imagined at least once, the global assessment of imagination may have biased results. That is, participants may have been biased into saying that most actions were imagined, because 
imagining was so frequent in the experiments. The number and frequency with which actions were imagined may have influenced participants' responses. This argument is weakened, though, by the fact that actions performed in Session 1 were not susceptible to this global assessment of imagination bias.

Actions that were performed in Session 1 were rarely misclassified as imagined, and as presentation increased in Session 2 this misclassification decreased. In fact, in Experiment 1, the proportion of times that participants erroneously claimed to have imagined actions increased from .08 (collapsing across familiar and bizarre) at zero imaginings to .12 at five imaginings in the simple imagining condition. This proportion decreased from .10 (collapsing across familiar and bizarre actions) at zero imaginings to .06 at five imaginings in the elaborate imagining condition. If participants were biased by the frequency of imagining in the experiments, they would have been more likely to erroneously classify all actions (performed or new) as imagined.

Turning our attention to the familiarity misattribution framework, imagining actions five times may have greatly increased participants' familiarity with those actions, leading them to make false did responses because they misinterpreted the strong familiarity as an indication that the actions had been performed (Goff \& Roediger, 1998). Indeed, text presentation led to an increase in false did responses. These results demonstrate that familiarity misattribution does play a role in the creation of false memories through imagination; however, the difference between the imagination conditions and the text presentation conditions would indicate that familiarity misattribution is not the sole contributor to the imagination inflation effect, and that participants also rely on the accessibility of perceptual information and more specific details when making judgments about memory.

Although the text presentation condition was developed to directly test the contributions of global familiarity, we also must consider that reading action statements may have led to the automatic generation of images. Previous research has shown that automatic images sometimes occur in response to short passages (Durso \& Johnson, 1980). If images occurred spontaneously in the text presentation condition, then the nature of the imagery could provide an additional cue used in source judgments. Unfortunately, as in much research investigating imagery, it is not possible to assess whether participants spontaneously generated images when reading action statements. Thus, the possibility that cues developed from these spontaneous images led to the modest increase in false did responses in the text presentation condition remains.

Finally, we must consider that reading may not have occurred in the text presentation condition; rather, the participants may have simply picked the longest words. If reading did not occur, it is possible that comprehension of action statements was hampered. Researchers have shown that familiarity misattribution does not occur in the absence of comprehension (Jacoby, Kelley,
\& Dywan, 1989). However, we interpret the small imagination inflation effect in the text presentation condition as evidence of the comprehension of action statements in that condition.

\section{Phenomenological Experiences of False Memories}

The effect of repeated imagining on false did responses was accompanied by an increase in $\mathrm{R}$ judgments. Furthermore, in both experiments, the participants who engaged in elaborated imagination were more likely to associate false $d i d$ responses with a conscious experience of remembering. The association of remember responses to false memories is consistent with the theory that the greater the vividness and distinctiveness of the remembered action, the greater the likelihood of the belief that it represents a true memory (Johnson \& Raye, 1981). Because participants were instructed to give $r e$ member responses for vivid, consciously remembered actions, it seems likely that elaborated imagining (as in the elaborate and individual conditions) increased the vividness and perceptual detail of actions, making them more like performed actions. Because fewer remember responses were given to actions in the text presentation condition, the participants probably had less specific detail with which to make memory judgments for actions in this condition. As with the source-monitoring results, our $\mathrm{R} / \mathrm{K}$ results are consistent with a source-monitoring account of false memories.

In sum, the results of these experiments suggest that false memories produced in an imagination inflation paradigm are primarily influenced by the reliance on specific and discrete memory characteristics, such as perceptual and sensory detail. When perceptual and sensory information is increased, false memories also increase. People use specific perceptual information to determine whether events were experienced or only thought about. These results not only help to differentiate two explanations for false memories, but also add to the growing body of literature concerning perceptual detail and false memory creation.

\section{REFERENCES}

Dobson, M., \& Markham, R. (1993). Imagery ability and source monitoring: Implications for eyewitness memory. British Journal of Psychology, 84, 111-118.

Drivdahl, S. D., \& Zaragoza, M. S. (2001). The role of perceptual elaboration and individual differences in the creation of false memories for suggested events. Applied Cognitive Psychology, 15, 265-281.

Durso, F. T., \& Johnson, M. K. (1980). The effect of orienting task on recognition, recall, and modality confusion of pictures and words. Journal of Verbal Learning \& Verbal Behavior, 19, 416-429.

GARDINER, J. M. (1988). Functional aspects of recollective experiences. Memory \& Cognition, 16, 309-313.

Garry, M., Frame, S., \& Loftus, E. F. (1999). Lie down and let me tell you about your childhood. In S. Della Sala (Ed.), Mind myths: Exploring popular notions about the mind and brain (pp. 113-124). Chichester, U.K.: Wiley.

Garry, M., Manning, C. G., Loftus, E. F., \& Sherman, S. J. (1996). Imagination inflation: Imagining a childhood event inflates confidence that it occurred. Psychonomic Bulletin \& Review, 3, 208-214. 
Goff, L. M., \& Roediger, H. L., III (1998). Imagination inflation for action events: Repeated imaginings lead to illusory recollections. Memory \& Cognition, 26, 20-33.

HEAPS, C., \& NASH, M. (1999). Individual differences in imagination inflation. Psychonomic Bulletin \& Review, 6, 313-318.

Henkel, L. A., Franklin, N., \& Johnson, M. K. (2000). Cross-modal source monitoring confusions between perceived and imagined events. Journal of Experimental Psychology: Learning, Memory, \& Cognition, 26, 321-335.

Jacoby, L. L., Allan, L. G., Collins, J. C., \& Larwill, L. K. (1988). Memory influences subjective experience: Noise judgments. Journal of Experimental Psychology: Learning, Memory, \& Cognition, 14, 240-247.

JACOBY, L. L., \& Dallas, M. (1981). On the relationship between autobiographical memory and perceptual learning. Journal of Experimental Psychology: General, 110, 306-340.

Jacoby, L. L., Kelley, C. M., Brown, J., \& JasechKo, J. (1989). Becoming famous overnight: Limits on the ability to avoid unconscious influences of the past. Journal of Personality \& Social Psychology, 56, 326-338.

JACoBy, L. L., Kelley, C. M., \& Dywan, J. (1989). Memory attributions. In H. L. Roediger III \& F. I. M. Craik (Eds.), Varieties of memory and consciousness: Essays in honour of Endel Tulving (pp. 391422). Hillsdale, NJ: Erlbaum.

Johnson, M. K., Foley, M. A., \& LeAch, K. (1988). The consequences for memory of imagining in another person's voice. Memory \& Cognition, 16, 337-342.

Johnson, M. K., Foley, M. A., Suengas, A. G., \& Raye, C. L. (1988). Phenomenal characteristics of memories for perceived and imagined autobiographical events. Journal of Experimental Psychology: General, 117, 371-376.

Johnson, M. K., Hashtroudi, S., \& Lindsay, S. D. (1993). Source monitoring. Psychological Bulletin, 114, 3-28.

Johnson, M. K., \& RAYE, C. L. (1981). Reality monitoring. Psychological Review, 94, 37-64.
Lindsay, D. S., \& Johnson, M. K. (2000). False memories and the source monitoring framework: A reply to Reyna and Lloyd (1997). Learning \& Individual Differences, 12, 145-161.

Moreland, R. L., \& ZaJonc, R. B. (1977). Is stimulus recognition a necessary condition for occurrence of exposure effects? Journal of Personality \& Social Psychology, 4, 191-199.

Paddock, J. R., Noel, M., Terronova, S., Eber, H. W., Manning, C. G., \& Lofrus, E. F. (1999). Imagination inflation and the perils of guided visualization. Journal of Psychology, 133, 581-595.

Pratkanis, A. R., Greenwald, A. G., Leippe, M. R., \& BaumgardNER, M. H. (1988). In search of reliable persuasion effects: III. The sleeper effect is dead: Long live the sleeper effect. Journal of Personality \& Social Psychology, 54, 203-218.

RAJARAM, S. (1993). Remembering and knowing: Two means of access to the personal past. Memory \& Cognition, 21, 89-102.

Suengas, A. G., \& Johnson, M. K. (1988). Qualitative effects of rehearsal on memories for perceived and imagined complex events. Journal of Experimental Psychology: General, 117, 377-389.

Thomas, A. K., \& Lofrus, E. F. (2002). Creating bizarre false memories through imagination. Memory \& Cognition, 30, 423-431.

Tulving, E. (1985). Memory and consciousness. Canadian Psychologist, 26, 1-12.

\section{NOTES}

1. For the sake of simplicity, throughout the rest of this article effects of number of imaginings will be presented parenthetically in ascending order [e.g., " $(.01, .06, .13)$ " in the present case].

2 . All statistical analyses reported on remember $(\mathrm{R})$ data were conducted on the proportion derived from the total $\mathrm{R}$ of the total number of actions in a condition. To control for differential rates of misattribution in imagination conditions, analyses of $\mathrm{R}$ data were also performed on the total $\mathrm{R}$ divided by the proportion of actions that the subjects said they "did," rather than by the proportion of all new actions. This conditionalized analysis did not yield results different from those reported.

\section{APPENDIX \\ Imagination Instructions for Experiments 1 and 2}

\section{Simple Imagining Instructions}

The experimenter read the following instructions to the participants:

In this part of the experiment, I am going to ask you to imagine various action statements. This task is similar to the imagination task you performed in Session 1. For example, I might ask you to imagine yourself getting up and opening the door. Once I state the action to be imagined, you must close your eyes and imagine yourself performing it. You will have 15 seconds to imagine the action. Please continue to imagine the action for the full 15 seconds, with your eyes closed. At the end of the 15 seconds, I will tell you to stop. At this time, you will rate how vivid the imagination was to you. If you give the imagination a rating of 1 , that means the imagination was not vivid. A rating of 5 means the imagination was extremely vivid.

[Example of an action statement read to the participants:] Imagine kissing the frog.

\section{Elaborate Imagining Instructions}

Instructions for elaborate imagination differed only in the example given to the participants. Instead of a one-sentence script, a three-sentence script that included sensory detail was provided. All elaborate imagination scripts were constructed prior to the session, and all scripts contained the original action followed by two sentences describing the imagination. No other specific guidance was given to the participants regarding imagination.

[Example of an action statement read to the participants:] Imagine kissing the frog. Imagine the color of the frog. Imagine the feel of the frog against your lips.

\section{Individual Imagining Instructions}

The experimenter read the following instructions to the participants:

In this part of the experiment, I am going to ask you to imagine various action statements. This task is similar to the imagination task you performed in Session 1; however, you will have to internally gener- 


\section{APPENDIX (Continued)}

ate two additional sentences to elaborate your imagination. For example, I might ask you to imagine yourself getting up and opening the door. Once I state the action to be imagined, you must close your eyes and imagine it. You must also internally generate two sentences that incorporate two different sensory modalities while imagining the action. You might also imagine how the door handle feels in your hand and how the door sounds as you open it. You will have 15 seconds to imagine the action. Please continue to imagine the action for the full 15 seconds, with your eyes closed. At the end of the 15 seconds, I will tell you to stop. At this time you will indicate which two sensory modalities you included in the imagination of the action.

[Example of an action statement read to the participants:] Imagine kissing the frog.

(Manuscript received June 8, 2002;

revision accepted for publication March 3, 2003.) 